\title{
Study of perinatal outcomes in normal and borderline oligamnios
}

\author{
Divya R. Prasad*, Neelima V. Nair
}

Department of Obstetrics and Gynecology, Sree Gokulam Medical College and Research Foundation, Venjaramoodu, Trivandrum, Kerala, India

Received: 15 November 2019

Accepted: 06 December 2019

\section{*Correspondence:}

Dr. Divya R. Prasad,

E-mail: ms.divanil@rediffmail.com

Copyright: (c) the author(s), publisher and licensee Medip Academy. This is an open-access article distributed under the terms of the Creative Commons Attribution Non-Commercial License, which permits unrestricted non-commercial use, distribution, and reproduction in any medium, provided the original work is properly cited.

\section{ABSTRACT}

Background: Oligamnios is a common cause of perinatal mortality and morbidity, but the outcome of borderline oligamnios, defined as Amniotic Fluid Index (AFI) between 5 and 8, is less clear. This study aims to find out the effect of borderline oligamnios on perinatal outcomes in pregnancies beyond 37 weeks.

Methods: An observational prospective study of 131 antenatal mothers with AFI between 5 and 8 , after 37 weeks of gestation was conducted in Sree Gokulam Medical College and Research Foundation from October 2017 to September 2019. These observations were compared with that of 131 antenatal mothers with normal AFI beyond 37 weeks of gestation. The observations according to fetal heart rate abnormalities, meconium staining of amniotic fluid, mode of delivery, low birth weight babies, APGAR score, the need of neonatal intensive care unit (NICU) admissions due to neonatal complications were statistically analysed.

Results: Both groups were comparable with respect to age, parity and gestational age. In those with borderline oligamnios, fetal heart rate abnormality was seen in $21 \%$ (28), meconium stained amniotic fluid in $18 \%$ (23), $70 \%$ (91) delivered vaginally and 30\% (40) underwent caesarean section, 31\% (41) babies weighed below $2.5 \mathrm{~kg}$ and $21 \%$ (27) neonates needed NICU admissions. In those with normal AFI, none showed fetal heart rate abnormality, 2\% (3) showed meconium staining, 93\% (122) delivered vaginally and 7\% (9) underwent caesarean section, 11\% (14) babies weighed below $2.5 \mathrm{~kg}$ and $3 \%$ (4) neonates needed NICU admissions.

Conclusions: Borderline oligamnios is associated with poor perinatal outcome. AFI can be used as an adjunct to other fetal surveillance methods. It helps to identify those infants at risk of poor perinatal outcome.

Keywords: Borderline oligamnios, Fetal distress, Fetal surveillance, Hypertension in pregnancy, Meconium staining, Perinatal outcome, Stillbirths

\section{INTRODUCTION}

Amniotic fluid volume represents a balance between outflow and inflow of fluid into the amniotic cavity. ${ }^{1}$ The most common intrinsic abnormality encountered clinically is reduced volume of amniotic fluid referred to as oligamnios. Oligamnios is defined as amniotic fluid index $(\mathrm{AFI})</=5 \mathrm{~cm}$, as originally described by Phelan et al. ${ }^{2}$ AFI between 5 and 8 is defined as borderline oligamnios. The incidence of oligamnios varies from 10 to $15 \%$ of all pregnancies. ${ }^{2}$ The common causes of oligamnios are intrauterine growth restriction, (IUGR), post term pregnancy, congenital anomalies, premature rupture of membranes and twin to twin transfusion syndrome. ${ }^{3}$ Most cases have no demonstrable cause and are classified as idiopathic or isolated oligamnios. Oligamnios is associated with variety of ominous pregnancy outcomes like fetal distress, low birth weight, perinatal morbidity, perinatal mortality and increased incidence of caesarean section. Various studies have not demonstrated significant perinatal morbidity in isolated oligamnios. The outcome of borderline AFI is less clear. This study aims to find out the perinatal outcome in pregnancies with borderline oligamnios. 
Aim of the study was to compare the perinatal outcomes of pregnancies with borderline amniotic fluid index to those with normal AFI.

\section{METHODS}

This is an observational prospective study conducted in the department of obstetrics and gynaecology, Sree Gokulam Medical College and Research Foundation for a period of 2 years, from October 2017 to September 2019. A total 131 antenatal mothers with borderline AFI after 37 weeks were compared to 131 antenatal mothers with normal AFI after 37 weeks.

\section{Inclusion criteria}

- All pregnant women beyond 37 weeks gestation, admitted in ward and labour room, and having singleton fetus in cephalic presentation, with normal AFI and borderline AFI were included in the study.

\section{Exclusion criteria}

- Multiple gestations

- Malpresentations

- Intrauterine growth restriction

- Associated fetal malformations

- Previous caesarean section

- Gestational hypertension, preeclampsia

- Associated medical complications.

Data was collected from all pregnant patients included in the study, using a proforma. Clinical evidence of decreased liquor was looked for and confirmed using ultrasound. These patients were followed up and various outcome measures were recorded which included fetal heart rate tracings, meconium staining of amniotic fluid, mode of delivery, indication for caesarean section, birth weight, APGAR score, admission to NICU and perinatal mortality. Data collected was entered in Microsoft excel and statistically analysed using SPSS software 20 . Outcome measures of those with borderline oligamnios was compared with those with normal AFI.

\section{Statistical analysis}

The statistical tests used were $\mathrm{F}$ test, Chi square test and t-test.

\section{RESULTS}

A total 131 pregnant women with AFI $>8 \mathrm{~cm}$ after 37 weeks gestation was compared with 131 pregnant women with AFI between 5 and 8 after 37 weeks gestation.

These 2 groups were comparable with respect to age, parity and gestational age at the time of delivery.

\section{AFI}

The amniotic fluid was measured by four quadrant amniotic fluid assessment technique using ultrasound. The mean AFI for those with borderline AFI was $7.52 \mathrm{~cm}$ and that for those with normal AFI was $11.86 \mathrm{~cm}$ (Table 1).

Table 1: Distribution of cases according to their AFI.

\begin{tabular}{|lll|l|}
\hline Borderline AFI & Mean & Normal AFI & Mean \\
\hline $5-5.9$ & 5.6 & $8.1-10$ & 9.21 \\
\hline $6-6.9$ & 6.4 & $10.1-13$ & 11.55 \\
\hline $7-7.3$ & 7.15 & $13.1-16$ & 14.6 \\
\hline $7.4-7.7$ & 7.55 & $16.1-18$ & 16.8 \\
\hline $7.8-8$ & 7.89 & $18.1-20$ & 18.4 \\
\hline Total & $\mathbf{7 . 5 2}$ & Total & $\mathbf{1 1 . 8 6}$ \\
\hline
\end{tabular}

*F-value 0.01932 , p-value $<0.05$.

\section{Fetal heat rate (FHR) abnormality}

FHR was monitored using cardiotocogram. FHR abnormalities were seen in $21 \%$ (28) of those with borderline AFI compared to none in those with normal AFI. Most common fetal heart rate abnormality was variable decelerations which were considered significant if it was below $70 \mathrm{bpm}$ and persisting for more than 60 seconds. There was significant difference between the two groups in occurrence of FHR abnormality (Table 2).

Table 2: Distribution of cases according to the fetal heart rate abnormality.

\begin{tabular}{|lllll|}
\hline \multirow{2}{*}{ FHR abnormality } & \multicolumn{3}{l|}{ Borderline AFI } & Normal AFI \\
\cline { 2 - 5 } & Number & \% & Number & \% \\
\hline Absent & 103 & 79 & 131 & 100 \\
\hline Present & 28 & 21 & 0 & 0 \\
\hline
\end{tabular}

$* \mathrm{X}^{2}$-value $31.35, \mathrm{P}$-value $<0.05$.

\section{Meconium staining of amniotic fluid}

The amniotic fluid was meconium stained in $18 \%$ (23) in those with borderline AFI. In those with normal AFI, only $2 \%$ (3) had meconium stained amniotic fluid (Table $3)$.

Table 3: Distribution of cases according to the color of liquor.

\begin{tabular}{|lllll|}
\hline \multirow{2}{*}{ Colour of liqour } & \multicolumn{2}{l|}{ Borderline AFI } & \multicolumn{2}{l|}{ Normal AFI } \\
\cline { 2 - 5 } & Number & \% & Number & \% \\
\hline Clear & 108 & 82 & 128 & 98 \\
\hline Meconium stained & 23 & 18 & 3 & 2 \\
\hline
\end{tabular}

$* \mathrm{X}^{2}$-value $17.92, \mathrm{P}$-value $<0.05$

\section{Mode of delivery}

A total $70 \%$ (91) delivered vaginally in those with borderline AFI and 93\% (122) in those with normal AFI. 
$30 \%$ (40) women underwent caesarean section in those with borderline AFI, whereas the rate of cs was $7 \%$ (9) in those with normal AFI (Table 4). Fetal distress and meconium stained amniotic fluid were the commonest indications for caesarean section.

Table 4: Distribution of cases according to the mode of delivery.

\begin{tabular}{|lllll|}
\hline \multirow{2}{*}{ Mode of delivery } & \multicolumn{2}{l}{ Borderline AFI } & Normal AFI \\
\cline { 2 - 5 } & Number & \% & Number & \% \\
\hline Vaginal delivery & 91 & 70 & 122 & 93 \\
\hline Caesarean section & 40 & 30 & 9 & 7 \\
\hline
\end{tabular}

$* \mathrm{X}^{2}$-test 25.62 , $\mathrm{p}$-value $<0.05$.

\section{Birth weight}

The mean birth weight was $2.90 \mathrm{~kg}$ in those with borderline AFI and $3.13 \mathrm{~kg}$ in those with normal AFI. The occurrence of birth weight $<2.5 \mathrm{~kg}$ was seen in $31 \%$ (41) and $11 \%$ (14) in those with borderline oligamnios and those with normal AFI respectively (Table 5).

Table 5: Distribution of cases according to birth weight of babies.

\begin{tabular}{|lllll|}
\hline \multirow{2}{*}{ Birth weight $(\mathrm{kg})$} & \multicolumn{2}{l|}{ Borderline AFI } & \multicolumn{2}{l|}{ Normal AFI } \\
\cline { 2 - 5 } & Number & $\mathbf{\%}$ & Number & \% \\
\hline$<1.5 \mathrm{~kg}$ & 0 & 0 & 0 & 0 \\
\hline $1.5-2.4 \mathrm{~kg}$ & 41 & 31 & 14 & 11 \\
\hline $2.5-3.4 \mathrm{~kg}$ & 72 & 55 & 90 & 69 \\
\hline $3.5-4.4 \mathrm{~kg}$ & 18 & 14 & 27 & 21 \\
\hline Total & $\mathbf{1 3 1}$ & $\mathbf{1 0 0}$ & $\mathbf{1 3 1}$ & $\mathbf{1 0 0}$ \\
\hline Mean & 2.90 & & 3.13 & \\
\hline SD & 0.52 & & 0.4 & \\
\hline
\end{tabular}

p-value $<0.05$.

\section{Apgar score}

The 1-minute Apgar score <9 was seen in 22\% (29) neonates of those with borderline AFI and in 3\% (4) of those with normal AFI (Table 6).

Table 6: Distribution of cases according to the Apgar score.

\begin{tabular}{|lllll|}
\hline Apgar $<9$ & \multicolumn{2}{c|}{ Borderline AFI } & \multicolumn{2}{c|}{ Normal AFI } \\
\hline & Number & \% & Number & \% \\
\hline 1 minute & 29 & 22 & 4 & 3 \\
\hline$* X^{2}$-test 0.137, p-value 0.711. & & \\
\hline
\end{tabular}

\section{NICU admissions}

A total $21 \%$ (27) neonates of those with borderline AFI were admitted in neonatal intensive care unit for various morbidities like birth asphyxia and meconium aspiration. Only 3\% (4) of those with normal AFI were admitted to NICU (Table 7).
There was no incidence of perinatal mortality in both the groups.

Table 7: Distribution of neonates according to their admission to NICU.

\begin{tabular}{|lllll|}
\hline Admission to & \multicolumn{2}{c|}{ Borderline AFI } & Normal AFI \\
\cline { 2 - 5 } NICU & Number & \% & Number & \% \\
\hline Yes & 27 & 21 & 4 & 3 \\
\hline No & 104 & 69 & 127 & 97 \\
\hline$* X^{2}$-test 19.35, p-value $<0.05$. & & & \\
\hline
\end{tabular}

Table 8: Comparison of neonatal complications of various studies.

\begin{tabular}{|llll|}
\hline Studies & $\begin{array}{l}\text { Apgar } \\
<9\end{array}$ & $\begin{array}{l}\text { Low birth } \\
\text { weight }\end{array}$ & $\begin{array}{l}\text { NICU } \\
\text { admission }\end{array}$ \\
\hline Sriya R et al & $38.8 \%$ & $58.38 \%$ & $88.88 \%$ \\
\hline Guin et al & $39 \%$ & & \\
\hline Chate P et al & $30 \%$ & $62 \%$ & $42 \%$ \\
\hline Our study & $22 \%$ & $31 \%$ & $21 \%$ \\
\hline
\end{tabular}

\section{DISCUSSION}

The concept of borderline oligamnios with ultrasound value of amniotic fluid volume between 5 and 8 was originally described by Phelan. ${ }^{2}$ Considering the adverse perinatal outcome in patients with borderline oligamnios and with oligamnios of AFI $<5$, there is still uncertainty about whether to manage these two groups similarly.

In the present study, both groups were comparable in terms of age, parity and gestational age.

Fetal heart abnormality was seen in $21 \%$ (28) of those with borderline oligamnios while no abnormality was found in those with normal AFI. In various studies by Gaikwad PR, it was $27.4 \%$, by Ghike et al, it was $44 \%$ and by Dasari et al, it was $23.8 \%$. $^{4-6}$

Amniotic fluid was meconium stained in $18 \%$ of those with borderline oligamnios and $2 \%$ of those with normal AFI. The difference is statistically significant. However, different studies seem to show different outcomes. Wood $\mathrm{L}$ et al, in their study could not show a statistically significant difference in the meconium staining of amniotic fluid. ${ }^{7}$

A total $70 \%$ (91) of those with borderline oligamnios delivered vaginally while $93 \%$ (122) of those with normal AFI delivered vaginally. The difference is statistically significant. The caesarean rate in those with borderline oligamnios was $30 \%$ (40). Petrozella et al, reported the caesarean rate to be $24 \%$ which is similar to our study. Common indications for caesarean section were fetal distress and meconium staining of amniotic fluid. ${ }^{8}$

In addition, the borderline oligamnios group had a higher rate of neonatal complications including 1-minute Apgar 
$<9$, low birth weight babies and NICU admissions. Similar results were seen in the studies by Sriya $\mathrm{R}$ et al, Guin et al, and Chate $\mathrm{P}$ et al (Table 8). ${ }^{9-11}$ The various reasons for NICU admissions included birth asphyxia and meconium aspiration.

No cases of perinatal or neonatal mortality was noted in either of the groups.

An AFI between 5 and $8 \mathrm{~cm}$ after 37 weeks of gestation is an indicator of adverse perinatal outcome. A higher rate of FHR abnormality, meconium stained amniotic fluid, fetal distress, increased rates of caesarean section, low Apgar scores, low birth weight babies and NICU admissions were seen in the borderline oligamnios group. So, these patients should be closely monitored during labour using intrapartum surveillance methods in order to avoid poor perinatal outcomes.

\section{CONCLUSION}

Borderline oligamnios is associated with poor perinatal outcome. AFI can be used as an adjunct to other fetal surveillance methods. It helps to identify those infants at high risk of poor perinatal outcome.

Funding: No funding sources

Conflict of interest: None declared

Ethical approval: The study was approved by the Institutional Ethics Committee

\section{REFERENCES}

1. Brace RA. Physiology of amniotic fluid regulation. Clin Obstet Gynecol.1997;40(2):280-9.

2. Phelan JP, Smith CV, Small M. Amniotic fluid assessment with four quadrant technique at 36-42 weeks of gestation. J Reprod Med. 1987;32:540-2.
3. Ross MG, Nijland MJ. Fetal swallowing: Relation to amniotic fluid regulation. Clin Obstet Gynecol. 1997;40(2):352-65.

4. Gaikwad PR, Oswal MS, Gandhewar MR, Bhatiyani PR. Perinatal outcome in oligohydramnios and borderline amniotic fluid index: a comparative study. Int J Reprod Contracept Obstet Gynecol. 2016;5:1964-8.

5. Ghike S, Reddy G, Ghike NW. Increasing severity of oligohydramnios: a risk factor for outcome. J South Asian Feder Obstet Gynecol. 2013;5(1):8-10.

6. Dasari P, Niveditta G, Raghavan S. The maximal vertical pocket and amniotic fluid index in predicting fetal distress in prolonged pregnancy. Int J Gynecol Obstet. 2007;96:89-93.

7. Wood Lindsay S, Michael Newton J, Liwang, Lesser $\mathrm{K}$. Borderline AFI and its relation to fetal intolerance of labour. J Ultrasound Med. 2014;33:705-11.

8. Petrozella LN, Dashe JS, McIntire DD, Leveno KJ. Clinical significance of borderline amniotic fluid index and oligohydramnios in preterm pregnancy. Obstet Gynecol. 2011;117:338-42.

9. Sriya R, Singhai S, Rajan M. Perinatal outcome in patients with amniotic fluid index less than $5 \mathrm{~cm}$. J Obstet and Gynecol of India. 2011;51(5):98-100.

10. Guin G, Punekar S, Leila A, Khare S. Prospective clinical study of fetomaternal outcome in pregnancies with abnormal liquor volume. J Obstet Gynecol. 2012;32(1):50-3.

11. Chate P, Khatri M, Hariharan C. Pregnancy outcome after diagnosis of oligohydramnios at term. Int $\mathrm{J}$ Reprod Contracept Obstet Gynecol. 2013;2(1):23-6.

Cite this article as: Prasad DR, Nair NV. Study of perinatal outcomes in normal and borderline oligamnios. Int J Reprod Contracept Obstet Gynecol 2020;9:279-82. 